\title{
Erratum to: The Association Between Obesity and Weight Loss Intention Weaker Among Blacks and Men than Whites and Women
}

Shervin Assari $^{1,2}$ - Maryam Moghani Lankarani ${ }^{2}$

Published online: 28 May 2015

(C) W. Montague Cobb-NMA Health Institute 2015

Erratum to: J. Racial and Ethnic Health Disparities DOI 10.1007/s40615-015-0115-x

The first author's correct name is Shervin Assari, not Assari Shervin. Rd., Ann Arbor 48109-2700, MI, USA

2 Center for Research on Ethnicity, Culture and Health, School of Public Health, University of Michigan, 2847 SPH I, 1415

Washington Heights, Ann Arbor, MI 48109-2029, USA 